\title{
TOWARDS MODEL BASED AUTOMATION - DIFFERENT TYPES OF 3-D MACHINE CONTROL MODELS FOR THE AUTOMATIC CONTROL OF ROAD CONSTRUCTION MACHINERY
}

\author{
Mika Jaakkola, Rauno Heikkilä \\ Oulu University, Research of Construction Technology \\ P.O. Box 4400 (Kasarmintie 4), FIN-90014 Oulu, Finland \\ rauno.heikkila@oulu.fi, mika.jaakkola@oulu.fi
}

\begin{abstract}
In this paper the type of CAD model-based automation is studied for the domain of infra construction tasks. The needs for machine control models vary from machine to machine. This paper describes as examples the machine control models needed for road graders, asphalt pavers, excavators, milling machines and steamrollers - the most typical work machines used in road construction activities. The paper also describes how these machine control models can be conducted from the product models. The usability of the control models was tested by on-site experiments using applicable automation systems. Furthermore, the necessary feedback from automated construction to the product model was also considered. This was done by measuring the quality and accuracy of the constructed work. In all and as a final conclusion, these tests represent and model the total process of road construction automation: what are the parts and how they work together.
\end{abstract}

Keywords: automation in road construction, 3-D CAD, machine control models

\section{INTRODUCTION}

Automation means self-acting or self-sustaining operation. The automated operation of machines can generally be divided into three different types: teach-in, model-based or fully autonomous operation. Teach-in is the simplest one. The machine is taught the necessary operation by driving a motion series using manual control. All of the motions of the used joints and regulating units are recorded at the deeded time intervals. It is also possible to repair a part of the whole taught motion. Finally, the machine can automatically repeat the driving it has been taught. Secondly, it is possible to generate a special machine control model on account of its earlier planned product model. This is a more advanced automation type. The availability of the product model is necessary. To utilize model to machine control we must calculate real-time and coordinate the needed motions for every part, joint and unit of the machine in question. For the most versatile applications all the kinematics must also be solved. Thirdly, it is possible to develop fully automated systems. The robot is equipped with the required number of sensors and it has the ability to operate in real-time and automatically generates its control model. All of the motions of different parts are calculated in real-time and through total kinematics and its inverse solutions.

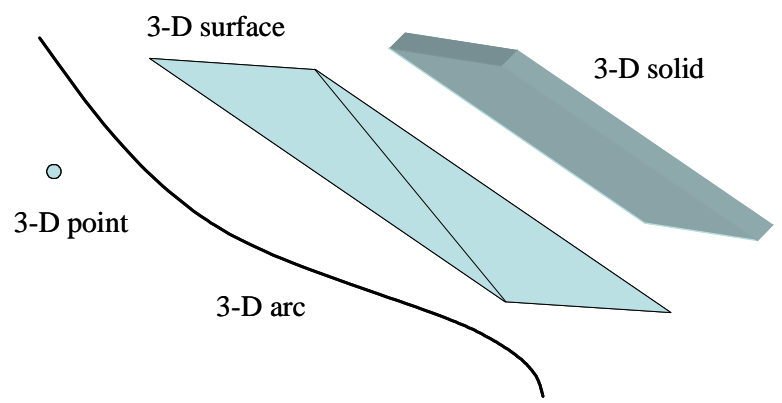

Figure 1. Basic 3-D geometric elements available for machine control applications.

\section{MODEL BASED ROAD CONSTRUCTION}

\subsection{Modeling process}

Preparing initial data for road geometry design starts with terrain modeling and ground surveying processes. Measured data is classified and translated for the utilization road geometry planning process (fig. 2). 
The general road geometry design method is composed of the next basic stages: horizontal geometry alignment, vertical geometry and cross section design. The road design process generates most of the required information for machine control. In particular, machine control (MC) models for road superstructure construction can be designed based on basic road geometry. Again the 3-D models produced in road design the CAD applications, cannot be used directly for machine control systems. Road geometry as 3-D arcs or lines are then transferred to machine control CAD tools. Finally, MC-models as 3-D surface models, staking out -lines, are produced to an applicable format for different MC control systems. On-site operation MC-models are used in MC-systems as a reference to guide the operator and directly to control the machine blade.

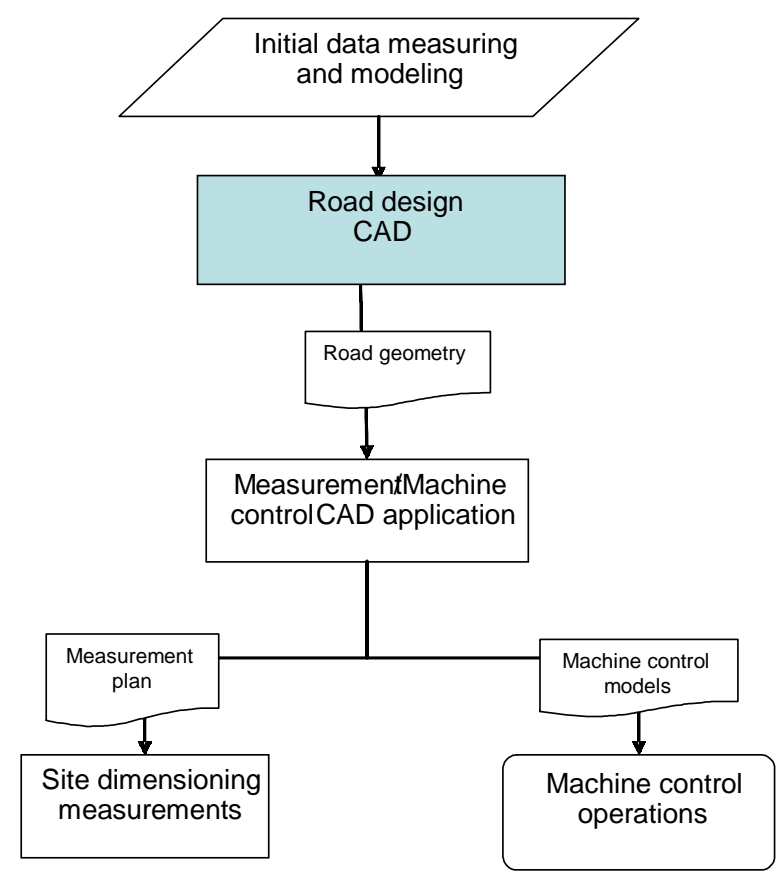

Figure 2. Information process from initial data measurements to site operations.

\subsection{Development needs of road design CAD applications}

According to a survey carried out among Finnish road design consultants in the spring of 2004, the main drawbacks of road design CAD software in structural modeling are related to the tools used for adapting the road cross sections and structures to the terrain. Areas where improvements are called for include the development of the modeling and crosssectional tools for structural geometry in such a way that the changes made to the cross section during design are automatically updated to the geometry of the lines and models and vice versa. Additionally, it should be possible to design the road alignment, leveling and cross section both visually and by using parameters. At the same time, the efficiency of the design system should be improved to allow quick comparison of different alignment and leveling options, inclusive of the calculation of quantities and relative costs. A shared goal for all road design CAD software developers is the adoption of standardized data transmission formats for input data entry and design data transfer to other systems. Another future objective is to put in a place a shared logic processing model for the entry and reprocessing of design data.

\section{TEST RESULTS}

The production of MC models is based on three items: firstly part of the road structure under construction work, second, the chosen working method and third, the machine type and the MC system involved. The MC modeling process is different depending on whether the focus is a new road or the renovation of an existing one.

For pavements and other super road structure layers, a typical MC model is 3-D surface model and 2D-control lines. This model only contains geometrical information about a road structure's elevation, the cross-fall and bending lines (convex or concave lines). The MC system can use the surface model for controlling elevation and cross-fall of a certain machine's blade. This kind of MC model can be used for controlling the motor grader, the paver and the milling machine (Fig.4). The same kind of MC model can also be utilized for an excavator when carrying out road sub-grade cutting and filling works. On the other hand consolidation work or the piling of road base requires different kinds of MC model (Figs.6 and 10).

The production phases of MC modeling for the road grader is presented in figure 3 . One important task in the modeling process is to 
connect different 3-D bending lines to form a continuous geometry. This also allows for the to creation of a continuous MC model, which has been proven to be profitable at on-site operations. For example, freeway lanes and the involved exits should integrate to the same MC model. Test results at freeway construction sites demonstrate that the extensive model minimizes the amount of possible breaks and provides better geometrical accuracy. Generally, a modelcontrolled grader is $50-100 \%$ more efficient than a traditional one. MC models produced for a grader can also be utilized for other machines, as a gravel spreader or a paver. The maximum benefit in model-based road construction is achieved when a group of machines are performing the same task and using the same MC models (Table 1).

The MC modeling process for the asphalt paver is basically the same as for the motor grader. The paver moves more slowly than the grader, but the required accuracy is more critical. The necessary level of automation in the paver is not as high as with a grader. The operator of the screeding blade still has enough time to control the blade himself, but at the same time he can take advantage of the MC system. In paving work, the invoicing basis is usually kilograms per square meter. In practice this concludes to contractor to make constant asphalt layer thickness. Despite the fact that MC models cannot always be used for controlling the thickness of the asphalt layer, cross slope and driving line guidance are valuable aspects to exploit. If concrete structures, such as bridges, are already modeled, these models can be put to good use in the paving process (fig. 9)

The geometrical MC modeling process for milling machine control depends on the level of road renovation work and the work method to be used. If renovation work concerns for example highway repavement the modeling process is basically the same as for the finisher. Before the MC modeling process is possible, the existing road geometry should firstly be measured and then the new geometry can be modeled. After that, road renovation design can be carried out in the 3-D CAD applications.

The milling machine is also used for cutting the old pavement and mixing it with the other road super structures. In Finland this is the common repair method for smaller roads. When the initial
3-D data is not available, an adequate MC model includes 2D-roadline and the amount of binder as well as the thickness of the layer to be stabilized (Fig. 5).

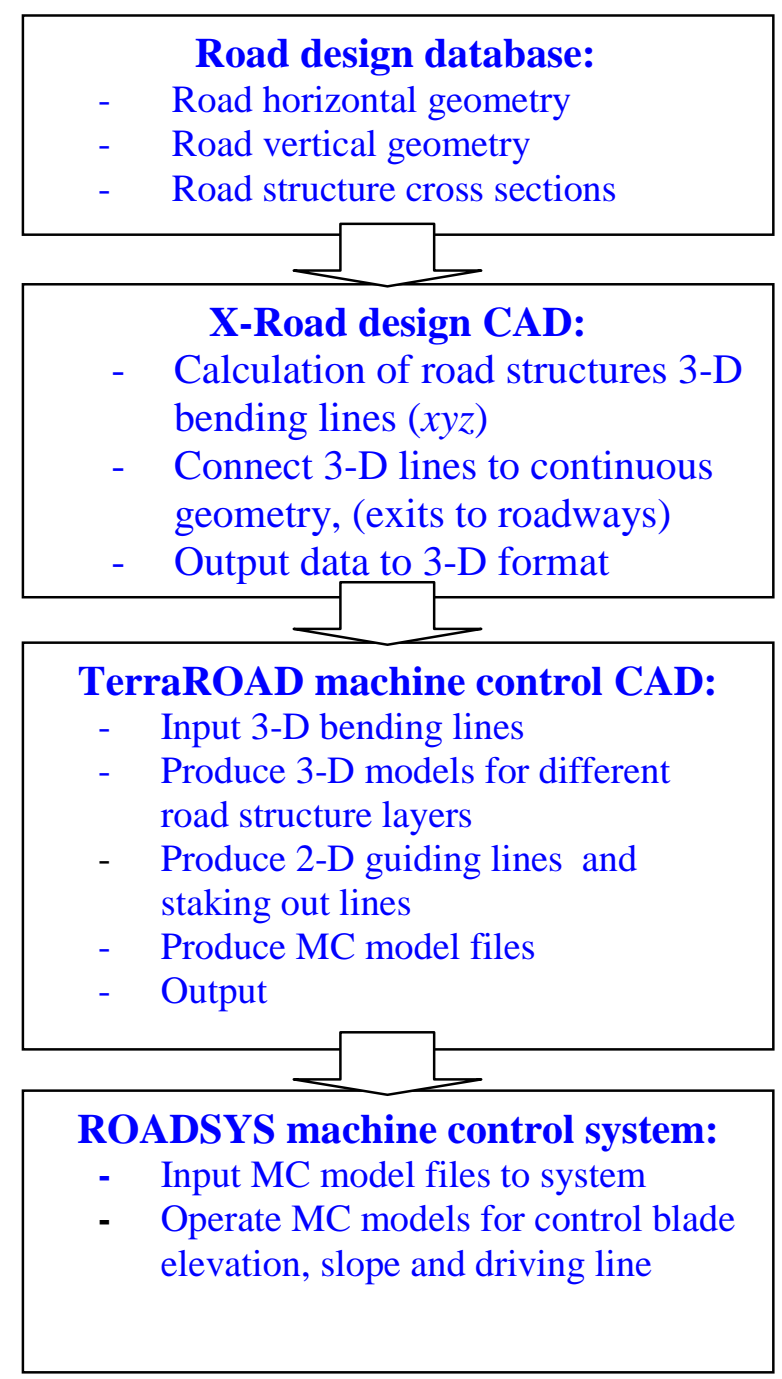

Figure 3. The phases and tools used to design MC models from the product models. 


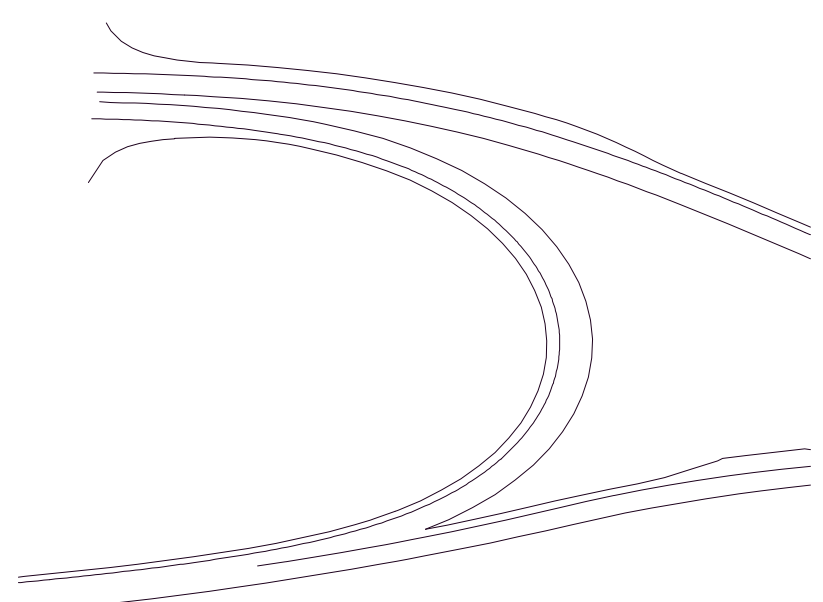

Figure 4. 3-D bending lines of the road structure layers are used as initial data for the MC model.

When an excavator is used for example in open cut or sub-base cutting works (fig. 7), the 3-D surface model of the structure is adequate initial information in order to produce the MC model. This model contains the required information about the structure's elevation and cross-fall. The excavator is typically used to finish the inner and outer slopes of the road ditch. In this case, in addition to the 3-D surface model, 3-D shoulder and ditch bottom lines are also needed for MC modeling.

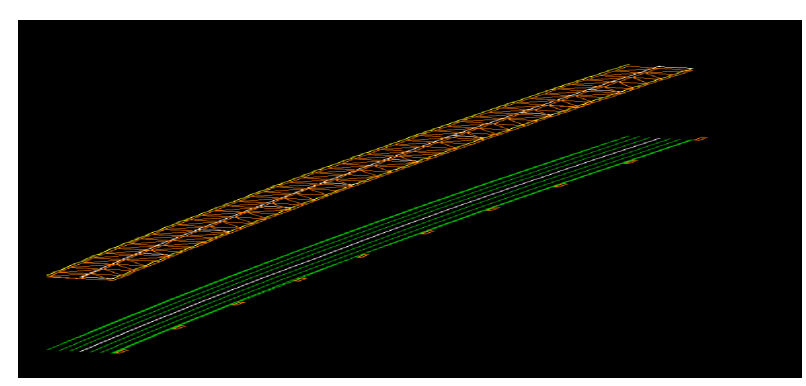

Figure 5. Type of machine control model for a road grader, mass spreader and asphalt paver: 3-D edge lines (lower) and height level (upper) is enough for most practical cases.

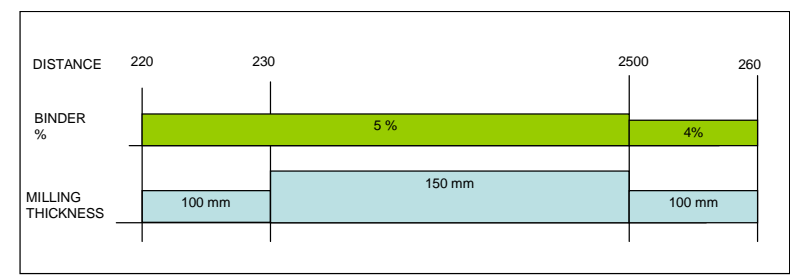

Figure 6. MC model required for milling machine. The necessary control items are the amount of binder as well as the thickness of layer to be stabilized.

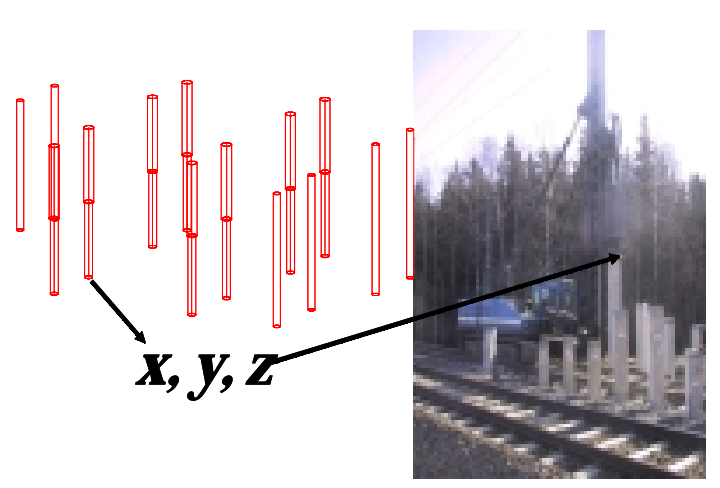

Figure 7. An example of machine control models:3-D locations of points for the piling machine.

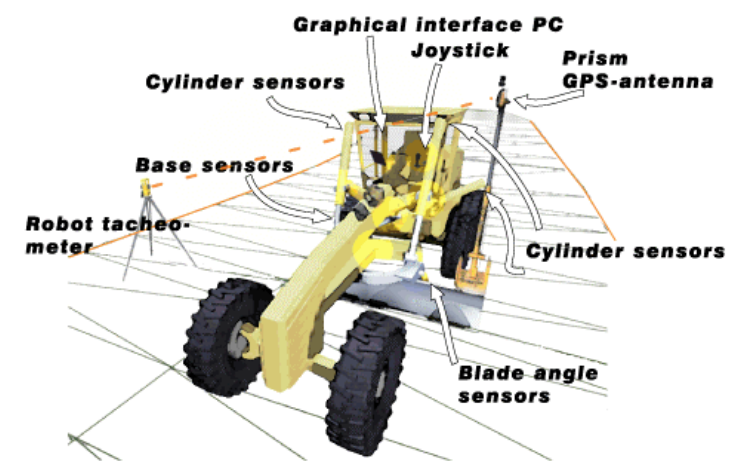

Figure 8. CAD model connected to the entirety of an automated control system of road grader.

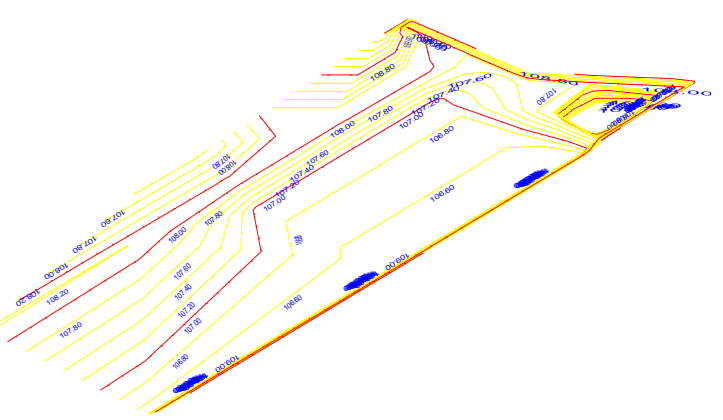

Figure 9. An example of an excavation machine control model -3-D model of a dump base. 


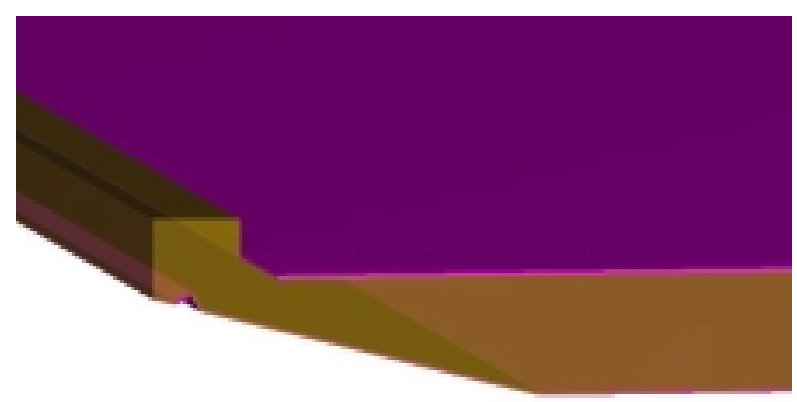

Figure 10. A model of a bridge superstructure can be used to control the paving process.

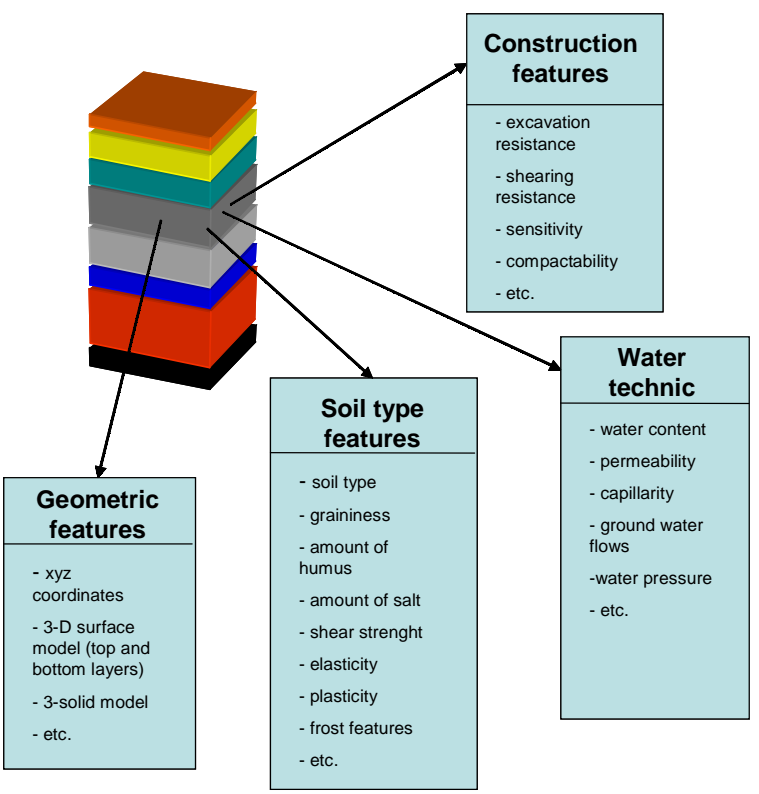

Figure 11. A sketch of advanced machine control models needed for stabilizing machines.

\section{CONCLUSION}

As far as road superstructures are concerned, solutions for producing workable control models for graders, pavers and excavators are already provided by existing software tools. Various machines used for carrying out the same work operations and implementing the same structures in road reconstruction can, to a great extent, make use of the same MC models based on 3D surfaces and lines.

Different types of CAD models are needed for the control of sub-base cementing work machines. The level of automation means that the required type and amount of information varies from machine to machine from very simple 3-D point models to complicated 3-D solid models integrated with numerous attributes.

A chief objective for model-based road construction is to develop site operations by improving productivity and the quality of structures. In principle, the existing models are easy to produce, provided that $3 \mathrm{D}$ plans are available for the site. With up-to-date tools, producing the models takes little time without affecting the economy of deploying MC systems.

The existing MC models are geometry models that include a mathematical surface plane as well as the horizontal geometrical lines of the bending lines. While they are accurate and reliable enough for controlling work machines, they are still unsuitable for more extensive automatic control of the site processes. Use of the existing models for road construction contributes to a better management of the site but it is safe to say that greater benefits can be expected when other information that supports and directs site activities, such as timetables, materials data or problem response procedures, can be incorporated in the models in addition to geometry data. Additional research is required to make it possible to use MC models beyond individual work machines for the purpose of controlling site activities more widely.

\section{REFERENCES}

Heikkilä, R. \& Jaakkola, M. \& Pulkkinen, M. (2003) Connecting 3-D Concrete Bridge Design to 3-D Site Measurements. ISARC'2003, 20th International Symposium on Automation and Robotics in Construction, 21-24 September 2003. Eindhoven, Netherlands, pp. 259-264.

Jaakkola, M. \& Heikkilä, R. \& (2003) Tutkimus 3D-suunnitteluprosessin kehittämistarpeista. Osaraportti III, Tienpidon digitaalisen toimintaprosessin kehittäminen ja rakentamisen automatisointi. Oulu, Rakentamisteknologian tutkimusryhmä, tutkimusraportti, $68 \mathrm{~s}$. 
Table 1. Work machine grouping road structure construction to be automated and estimation of automation needs and benefit potentials.

\begin{tabular}{|c|c|c|c|}
\hline Working task & Machine & Automated functions & Benefit potentials \\
\hline Loading & Wheel loader & $\begin{array}{l}\text { Load scale, wireless } \\
\text { data transfer }\end{array}$ & Material savings \\
\hline $\begin{array}{l}\text { Transport and } \\
\text { unloading }\end{array}$ & Kuorma-auto & $\begin{array}{l}\text { Documentation of } \\
\text { loading data }\end{array}$ & $\begin{array}{l}\text { Material savings, } \\
\text { Work method } \\
\text { efficiency }\end{array}$ \\
\hline Gravel spreading & Gravel spreader & $\begin{array}{l}\text { 3-D control system : } \\
\text { layer thickness, cross } \\
\text { slope, driving direction }\end{array}$ & $\begin{array}{l}\text { Material savings, } \\
\text { quality, surveying } \\
\text { costs } \mathbf{- 5 0 \%}\end{array}$ \\
\hline $\begin{array}{l}\text { Milling and } \\
\text { stabilization }\end{array}$ & Milling machine & $\begin{array}{l}\text { 2D/3D control system: } \\
\text { milling thickness, binder } \\
\text { quantity, cross slope, } \\
\text { driving direction, } \\
\text { documentation }\end{array}$ & $\begin{array}{l}\text { Material savings, - } \\
\mathbf{2 \%} \text {, surveying costs - } \\
\mathbf{5 0 \%} \text {, quality benefits }\end{array}$ \\
\hline Finishing & Motor Grader & $\begin{array}{l}\text { 3-D blade control } \\
\text { system: blade control in } \\
\text { all directions }\end{array}$ & $\begin{array}{l}\text { Capacity }+\mathbf{5 0 - 1 0 0 \% ,} \\
\text { material savings } 3 \% \text {, } \\
\text { surveying costs } \\
50 \%, \text { documentation }\end{array}$ \\
\hline Paving & Asphalt paver & 3D-control system: & $\begin{array}{l}\text { Material savings } \\
\mathbf{2 \%}, \text { surveying costs } \\
\mathbf{5 0 \%} \text {, documentation }\end{array}$ \\
\hline Compaction & & $\begin{array}{l}\text { 2-D control system: } \\
\text { documentation of } \\
\text { density, driving control }\end{array}$ & $\begin{array}{l}\text { Quality of road } \\
\text { structure }\end{array}$ \\
\hline
\end{tabular}

